\title{
Sensitivity Analyses of Intact and Damage Stability Properties to Passenger Ship's Dimensions and Proportions
}

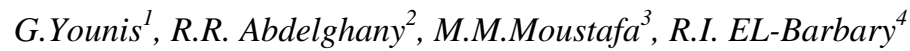

\begin{abstract}
Demand for cruise ships has increased significantly in recent years. The design of passenger vessels has changed significantly to reflect customer requirements and the need to increase income earning capacity. The current investigation aims to understand the impact of changing the main dimensions or form proportions on the ship's stability and the allowed limitation to KG. The study is performed to evaluate the sensitivity of the intact and damage stability properties as well as the limiting KG for intact and damage stability after changing the main dimensions of a passenger ship.
\end{abstract}

KEYWORDS: Passenger ships-stability - IMO criteria - Limiting KG - SOLAS criteria - ship dimensions - proportions.

\section{SYMBOLS AND ABBREVIATIONS}

ILLC: International Load Line Convention SOLAS: The Safety of Life at Sea Convention IMCO: International Maritime Organization(original name) IMO : International Maritime Organization IS Code: The Intact Stability Code of IMO Convention GM: Metacentric height, $\mathrm{m}$

KB: height of the vertical center of bouyancy above keel, $m$ BM: transverse metacentric radius, $m$

KG: height of the center of gravity of a ship above keel, $m$

$\mathrm{GZ}$ : righting lever, $\mathrm{m}$

$\mathrm{GM}_{0}$ :Initial metacentric height, $\mathrm{m}$

$K G_{C_{I_{\mathrm{n}}}}$ :Limiting $\mathrm{KG}$ according to intact stability criteria, $\mathrm{m}$ $K G_{C_{D_{\mathrm{n}}}}$ :Limiting KG according to damage stability criteria, $\mathrm{m}$

\section{INTRODUCTION}

The vessel may be unstable due to existing forces, whether due to internal or external factors depending on their sources. The sources of these forces are common among all types of ships, but there are more related sources of passenger ships represented in crowding of passengers to one side and High Speed Turning Maneuvers [1], [2].

The most important steps of evolution in the field of ship's stability are described in the following subsections:

It is known that the analysis of the causes of casualties by scientists and specialists in the field of stability of ships caused the development of mandatory laws in the design of the latest ships in order to avoid the recurrence of the same incidents as much as possible.

\footnotetext{
${ }^{1}$ Professor, Naval Architecture and Marine Engineering, Port Said University, Port Said, Egypt, E-mail: dr.galal@eng.psu.edu.eg com

2Lecturer, Naval Architecture and Marine Engineering

,Port Said University, Port Said, Egypt, E-mail: randaramadan@eng.psu.edu.eg

3Lecturer, Naval Architecture and Marine Engineering , Port Said University, Port Said, Egypt, E-mail: moustafa3875@eng.psu.edu.eg

4Demonstrator, Naval Architecture and Marine Engineering, Port Said University, Port Said, Egypt, E-mail: ranaelbarbary88@eng.psu.edu.eg
}

For example, the following legislations have been added:

- The international regulations for the subdivision of the hull into watertight compartments were being formed in response to the Titanic disaster. On 20 January 1914 in London, a meeting was held to adopt the international Convention of the Safety of Life at Sea (SOLAS) [1].

- Changing in safety regulations as well as in life raft design in response to the MTS Oceanos disaster[2].

- the North West European nations established very strict regulation on damage stability for Ropax ship, which is known as the Stockholm Agreement, demanding that a vessel satisfies SOLAS '90 requirements in addition to considering water on deck with a constant height rather than a constant amount of water in response to the MS Estonia disaster [3].

\section{EVOLUTION OF STABILITY STUDIES}

\subsection{The beginning of stability's history}

The principles governing the design of ships are the principles of Archimedes of buoyancy and stability of floating objects (balance of moments) in 300BC [4].

Since 1747, the metacenter was being defined by Bouguer, the restoring moment was described by Euler. In 1757, Bernoulli introduced dynamic stability [5].

In September 1870, the HMS Captain capsized while the HMS Monarch had similar dimensions and the same initial stability but succeeded in sailing as a result of the difference of the freeboard, led to a difference in stabilities at large angles, This had attracted the attention of the English naval architect Edward Reed, chief constructor of the Royal Navy, to the importance of reserve stability associated with a minimum freeboard to the main deck in case of large inclinations. In 1875, Great Britain has passed legislation that requires placing a mark (Plimsoll mark) on each ship's side to prevent overloading and became mandatory legislation in 1890. Moreover in 1904 , German has passed rules, These two sets of rules included minimum freeboard, strength, hull integrity, and safety movement of persons on board in 1913 [4], [6].

The British government invited for the regulation of a unified international Convention and the mandatory rules for all ships but because of the World War I, this conference was delayed to 1930, (First International Load Line Convention (ILLC)) [4]. 


\subsection{The beginning of the modern age}

After the sinking of Titanic, the international maritime safety societies held an agreement in London in 1914 known as the Safety of Life at Sea (SOLAS), "Ocean-going steamvessels which carry passengers should be additionally protected by having efficient bulkheads, so spaced that when two compartments are damaged, the vessel will still afloat in a seaworthy condition, and at least two of the amidships bulkheads should be tested by water pressure to the height of the deck next above the water-line"; The Convention was later met in 1929 and 1948. The outbreak of World War I and World War II had their effect in preventing the application of the first two SOLAS at an international level [7].

It can be said that the beginning of the stability criteria was in the 30s of the last century which was largely based on two papers. The first of them, Pierrottet (1935) established what would later be known as the standard of the Weather Criterion. However, the results of his research were not included in the mandatory laws, because at this time, the number of vessels subjected to incidents of coup were considered relatively low. Second came the Ph.D. thesis of Rahola (1939) which determined minimum stability criteria after statistics of 14 vessels that capsized between 1870 and 1938 [6], [8].

Also in 1939, Vincent [6] contributed to laying the first Principles of Naval Architecture to achieve safety from capsizing and comfort for passengers.

the IMCO sub-committee on subdivision and stability was formed in 1962 in response to a recommendation outlined in the conclusions of SOLAS'60, The first international stability criterion, Resolution A.167, was the development of Rahola's GZ criteria, was adopted by the IMO in 1968 for ships under $100 \mathrm{~m}$. This statistical criterion was related to static and dynamic stability [4], [7].

The external forces which may lead to capsize ships was taken into consideration based on the recommendations of SOLAS'74, Accordingly IMO adopted the weather Criterion in 1985 by IMO Resolution A.562 [4].

The main IMO branches for dealing with safety of ships today are as follows:

1. The SOLAS Convention, which deals with the subdivision of ships and stability after damage.

2. The ILLC, which deals with the minimum freeboard of ships.

3. The Intact Stability Code (the IS Code), in 1968, related to the minimum standards for intact ship static and 'dynamic' stability characteristics [4].

These standard criteria continue to evolve to this day as a result of the occurrence of accidents for some ships to avoid recurrence in the future as much as possible and to keep pace with new developments in ship design [4].

\subsection{Harmonisation process of existing and new regulations}

The new probabilistic damaged stability assessment concept for dry cargo and passenger ships (MSC80) enter into action began after January 1, 2009 (SOLAS 2009), This was the culmination of more than 50 years of work which is considered one of the longest working periods in any other safety regulation [9].

It is therefore possible to say that there are two main categories of ship's damage stability regulatory that are currently in use. Both categories are leading to the corresponding regulatory stability criteria [10]:
1. Namely the deterministic approach which is based on prescriptive, semi-empirical rules and criteria derived from statistical analysis of historical damage data and practical experience.

2. The probabilistic approach which relies on a rational statistical assessment of historical accidental data combines this statistical information with semiempirical criteria. More rationally, this would lead to assess the ship's survivability using some probabilistic concept that takes into account a vast amount of possible damage scenarios with proper weight.

In line with SOLAS 60; the fundamentals of a new probabilistic model for the assessment of ships watertight subdivision began by Professor Kurt Wendel from Germany which enabled the consideration of possible damage scenarios in a rational manner [6].After many elaboration periods; the discussions of the necessity of revising the deterministic evaluation of watertight subdivision of passenger ships by the technical IMO subcommittees, have found that it is best to harmonize all damage stability regulations under a unified probabilistic framework for all types of merchant ships (cargo and passenger ships), rather than updating the current deterministic compartmentation standards for passenger ships [9].

\section{THE LIMITING KG AND THE LIMITING DEADWEIGHT MOMENT}

The maximum values of the vertical location of the center of gravity (KG allowed) are the best criteria for the stability of the vessel as well as the maximum permissible dead weight moment which is the maximum allowable value of the moment of passengers / cargo, fresh water, fuel stores, etc. about the keel, considering free surface moment.

So it can say that to ensure a good selection of design dimensions - especially for Passenger ships which are harmfully influenced if subjected to any underwater hull damage that is due to the higher permeability of the spaces under bulkhead deck- it should be used to insure a sufficiently high limiting $\mathrm{KG}$ for the ship satisfying the IMO - SOLAS criteria which requires the investigation of the effects of ship's design parameters on the limiting $\mathrm{KG}$ in intact and damaged conditions, this could be done during the early stages of design process.

\subsection{Methods to calculate the limiting KG}

\subsubsection{The approximate method to calculate the limiting KG}

This method depends on Prohaska equation. It is used primarily in the absence of ship lines to help predict the distribution of loads vertically and the general arrangement. The results of this method are different from the estimated results from cross curves of the investigated ships within $0.15 \%$ to $5.4 \%$ [11].

$$
G Z=G M \sin \theta+B M * C R_{\Theta}
$$

Where as shown in Figure 1 [12]:

$$
C R_{\ominus}=\frac{M S}{B M_{T}}
$$




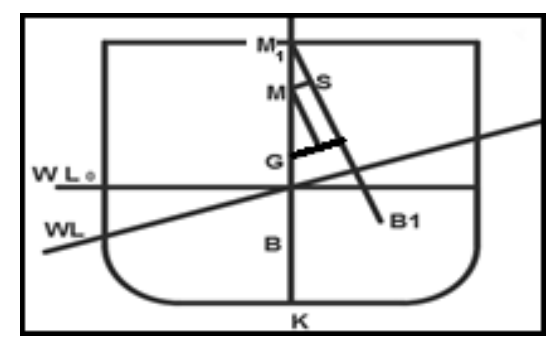

Figure 1: Stability at large angles [12]

and by using Euler's formulae (1):

$$
\begin{gathered}
B M=\frac{C W^{3} * B^{2}}{2 * C B * T *(C W+1) *(2 * C W+1)} \\
K B=\frac{C W * T}{C W+C B}
\end{gathered}
$$

Where $\quad C W=0.75605 * C B+0.2725$

Critical values of GM could be determined by integrating the GZ values up to the required angles to satisfy the stability standards criteria.

The limiting value of $\mathrm{KG}$ can calculated as following

$$
K G_{C}=K B+B M-G M_{\min }
$$

\subsubsection{The analytical method to calculate the limiting KG}

This method depends on Kryloff's equation of righting levers. But the ship's lines and the ship's form information have to be provided [11].

$$
G Z=Y_{F} * \cos \theta+Z_{F} * \sin \theta-\left(K G_{L_{n}}-K B_{0}\right) * \sin \theta
$$

$$
\begin{aligned}
Y_{F} & =\int_{0}^{\theta} B M_{\theta} * \cos \theta d \theta \\
Z_{F} & =\int_{0}^{\theta} B \sin \theta d M_{\theta} * \theta
\end{aligned}
$$

Where $B M_{\theta}$ is the metacentric radius at angle $\theta$.

$K G_{L_{n}}$ is the limiting $\mathrm{KG}$ to satisfy the (n) stability standard

$K B_{0}$ is the initial vertical center of buoyancy at the specified displacement investigated

\subsection{The limiting KG according to IMO standards of intact stability criteria}

The IMO Resolution (2008 IS Code) regarding intact stability for passenger ships (part A is mandatory part) could be expressed in the form of standards which are stipulated as minima for this type of ships [7] ,these standards are:

Standard I 1: The area under GZ curve between angles of heel from $0^{0}$ to $30^{0} \geq 0.055$ meter-radians.

Standard I 2: Area B is the area under GZ curve between angles of heel from Area $0^{\circ}$ to $\left(40^{\circ}\right.$ or $\left.\varphi_{\mathrm{f}}\right)$ whichever less $\geq$ 0.09 meter-radians $\left(\varphi_{\mathrm{f}}\right.$ is the down flooding angle).

Standard I 3: the area under GZ curve between angles of heel from Area $30^{\circ}$ to $\left(40^{\circ}\right.$ or $\left.\varphi_{\mathrm{f}}\right)$ whichever is less $\geq 0.03$ meter-radians

Standard I 4: Max GZ $\geq 0.2$ meter at angle $\geq 30^{\circ}$

Standard I 5: Initial $\mathrm{GM}_{0} \geq 0.15$ meter

Additional Standard I 6: Many government regulations set an additional criterion specified a minimum range of positive stability is $50^{\circ}[11]$

The limiting $\mathrm{KG}$ can be calculated for each standard criterion by using formula (4), (5)and (6); Knowing that this limiting $\mathrm{KG}$ value of them is the maximum allowable [11].
1. For satisfying stability standard I 1 : $\mathrm{A} 00^{\circ}$ to $30^{\circ}=$ $0.055 \mathrm{~m} . \mathrm{rad}$

$$
\begin{gathered}
\int_{0}^{\theta=30} G Z d \theta=0.055 \\
K G_{C_{I_{1}}} \\
=\frac{\int_{0}^{\theta=30} Y_{F} * \cos \theta d \theta+\int_{0}^{\theta=30} Z_{F} \sin \theta d \theta-0.055}{\int_{0}^{\theta=30} \sin \theta d \theta} \\
+K B_{0}
\end{gathered}
$$

2. For satisfying stability standard I 2: A $0^{\circ}$ to $40^{\circ}=0.09$ m.rad

$$
\begin{gathered}
\int_{0}^{\theta=40} G Z d \theta=0.09 \\
K G_{C_{I_{2}}} \\
=\frac{\int_{0}^{\theta=40} Y_{F} * \cos \theta d \theta+\int_{0}^{\theta=40} Z_{F} \sin \theta d \theta-0.09}{\int_{0}^{\theta=40} \sin \theta d \theta} \\
+K B_{0}
\end{gathered}
$$

3. For satisfying stability standard I 3: A $30^{\circ}$ to $40^{\circ}=0.03$ m.rad

$$
\int_{0}^{\theta=40} G Z d \theta-\int_{0}^{\theta=40} G Z d \theta=0.03
$$

$K G_{C_{I_{3}}}=$

$\frac{\int_{0}^{\theta=40} Y_{F} * \cos \theta d \theta-\int_{0}^{\theta=30} Y_{F} * \cos \theta d \theta+\int_{0}^{\theta=40} Z_{F} \sin \Theta d \theta-\int_{0}^{\theta=30} Z_{F} \sin \Theta d \theta-0.03}{\int_{0}^{\theta=40} \sin \theta d \theta-\int_{0}^{\theta=30} \sin \theta d \theta}+$ $+K B_{0}$

4. For satisfying stability standard I 4: GZ $\max =0.2$ meter at $\mathrm{\theta}=30^{\circ}$

$$
K G_{C_{I_{4}}}=
$$$$
\frac{\cos 30 * \int_{0}^{\theta=30} B M_{\theta} * \cos \theta d \theta+\sin 30 * \int_{0}^{\theta=30} B M_{\theta} * \sin \theta d \theta-0.20}{\sin 30}+K B_{0}
$$

5. For satisfying stability standard I $5: \mathrm{GM}_{0}=0.15 \mathrm{~m}$

$$
K G_{C_{I_{5}}}=K B_{0}+B M_{0}-0.15
$$

6. For satisfying stability additional standard I 6: $\mathrm{GZ}=0$ at $\Theta=50^{\circ}$

$$
\begin{aligned}
& K G_{C_{I_{6}}}= \\
& \frac{\cos 50 * \int_{0}^{\theta=50} B M_{\theta} * \cos \theta d \theta+\sin 50 * \int_{0}^{\theta=50} B M_{\theta} * \sin \theta d \theta-0.20}{\sin 50}+K B_{0}
\end{aligned}
$$

\subsection{Limiting KG with respect to SOLAS standard damage stability criteria}

The damage stability criteria for passenger ships, which are stricter than those for cargo ships, according to SOLAS 2008; Regulation 8 of the convention specifies the criteria of stability in the final condition after damage as follows [13]:

-In intermediate stages of flooding:

Standard D 1: $\mathrm{GZ}_{\max } \geq 0.05 \mathrm{~m}$; range of positive righting levers shall be at least $7^{\circ}$

- In the final condition after damage:

Standard D 2: $\mathrm{GM}_{\mathrm{MIN}} \geq 0.05$ meter

Standard D 3: 2. The area under the righting-arm curve should be at least $0.015 \mathrm{~m} \mathrm{rad}$. 
Standard D 4: residual GZ $\max \geq 0.1$ meter, Considering the heeling moment due to crowding passengers or wind heeling (whichever is greater).

Standard D 5: range of positive residual arm $\geq 15^{\circ}$

Standard D 6: In no case shall the margin line shall be not submerged in the final stage of flooding at any case.

Standard D7: In case of unsymmetrical flooding; the list being not more than $7^{\circ}$.

\section{i. Intermediate stages of flooding}

1. For satisfying stability standard D $1: G Z_{M A X_{\mathrm{ISS}}}=0.05 \mathrm{~m}$ at $\theta=7^{\circ}$

$$
K G_{C_{D_{1}}}=\frac{\Delta_{D_{1}} * G_{D_{1}}-W * V . c . g}{\Delta}
$$

Where

$$
G_{D_{1}}=\frac{\cos 7 * \int_{\emptyset_{E Q}}^{\theta=7} B M_{\theta} * \cos \theta d \theta+\sin 7 * \int_{\emptyset_{E Q}}^{\theta=7} B M_{\theta} * \sin \theta d \theta-0.05}{\sin 7}+
$$

Where:

$\emptyset_{E Q}=$ Angle of equilibrium

$G_{D}=$ The maximum permissible $\mathrm{KG}$ after damage

$K G_{D}=$ The corresponding limiting intact $\mathrm{KG}$

$\mathrm{FS}=$ Free surface correction of the flooded surface

$\Delta=$ Intact displacement

$\Delta_{D}=$ Damage displacement

$\mathrm{W}=$ Weight of invading water

V.c.g = Vertical center of gravity of invading water

$\mathrm{BM}_{\mathrm{D}}=$ Metacentric radius in damaged condition

$\mathrm{KB}_{\mathrm{D}}=$ Vertical Center of buoyancy in damaged condition.

ii. In the final condition after damage:

- In case of symmetrical flooding

2. For satisfying stability standard D 2: $G M_{M I N}=0.05 \mathrm{~m}$

$$
K G_{C_{D_{2}}}=\frac{\Delta_{D} * G_{D_{2}}-W * V . c . g}{\Delta}
$$

Where

$$
G_{D_{2}}=B M_{D}+K B_{D}-\mathrm{FS}-0.05
$$

3. For satisfying stability standard D $3: \mathrm{A}_{\boldsymbol{\varphi} \mathbf{E Q}}{ }^{\mathbf{0}}$ to $\boldsymbol{\theta}^{\mathbf{0}}$ $=0.015 \mathrm{~m} . \mathrm{rad}$

$$
\begin{array}{r}
\int_{\emptyset_{E Q}}^{\ominus} G Z d \theta=0.015 \\
K G_{C_{D_{3}}}=\frac{\Delta_{D_{3}} * G_{D_{3}}-W * V . c . g}{\Delta}
\end{array}
$$

Where

3.1 at one compartment is flooded

$$
G_{D_{3}}=\frac{\int_{\emptyset_{E Q}}^{\theta=22} Y_{F} * \cos \theta d \theta+\int_{\emptyset_{E Q}}^{\theta=22} Z_{F} \sin \theta d \theta-0.015}{\int_{\emptyset_{E Q}}^{\theta=22} \sin \theta \mathrm{d} \theta}+K B_{0}-f S
$$

3.2 at two compartments is flooded

$$
G_{D_{3}}=\frac{\int_{\emptyset_{E Q}}^{\theta=27} Y_{F} * \cos \theta d \theta+\int_{\emptyset_{E Q}}^{\theta=27} Z_{F} \sin \theta d \theta-0.015}{\int_{\emptyset_{E Q}}^{\theta=22} \sin \theta \mathrm{d} \theta}+K B_{0}-f S
$$

4. For satisfying stability standard D 4: GZ max $=0.1$ meter

$$
K G_{C_{D_{4}}}=\frac{\Delta_{D_{4}} * G_{D_{4}}-W * V . c . g}{\Delta}
$$

Where

$$
\begin{aligned}
& G_{D_{4}}=
\end{aligned}
$$

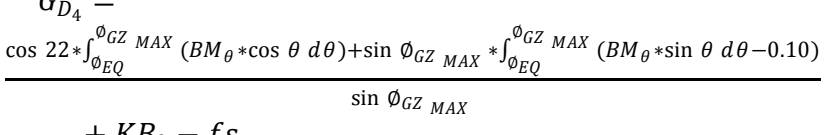

$$
\begin{aligned}
& +K B_{0}-f s
\end{aligned}
$$

5. For satisfying stability standard D 6: In no case shall the margin line shall not be submerged in the final stage of flooding at any case.

This is not related directly to the $\mathrm{KG}$ of the ship and is governed through the floodable length calculations.

- In case of unsymmetrical flooding

6. Standard D7: The list being not more than 7 degrees.

$$
K G_{C_{D_{7}}}=\frac{\Delta_{\mathrm{D}_{7}} * \mathrm{G}_{\mathrm{D}_{7}}-\mathrm{W} * \text { V.c.g }}{\Delta}
$$

Where

$$
\begin{gathered}
\mathrm{G}_{\mathrm{D}_{7}}=\mathrm{BM}_{\mathrm{D}}+\mathrm{KB}_{\mathrm{D}}-\mathrm{FS}-G M_{D} \\
\mathrm{GG}_{\mathrm{D}}=\frac{\mathrm{W} * \text { t.c.g }}{\Delta} \\
G M_{D}=G G_{D} * \tan 7
\end{gathered}
$$

t.c.g = Transverse center of gravity of invading water

$\mathrm{GM}_{\mathrm{D}}=$ Metacentric height in damaged condition

$\mathrm{GG}_{\mathrm{D}}=$ Transverse shift of center of gravity of the ship after damage.

\subsection{Deadweight moment}

The maximum deadweight moment is given by

\section{Limiting Deadweight moment}

$=$ Deadweight $x$ max. Limiting KG of this weight

As shown in Figure 2, the Deadweight Moment in tonmeters on the abscissa against displacement in tons on the ordinate is known as the curve of maximum Permissible Deadweight Moments which represent one form of a simplified stability data diagram.

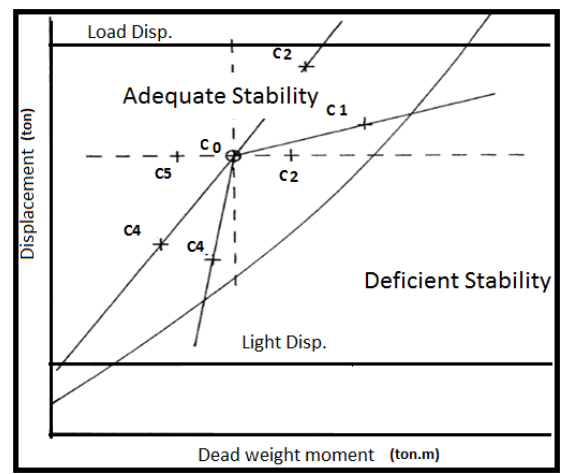

Figure 2 : Use of deadweight moment diagram[14].

Where in Figure $2, \mathrm{C} 0, \mathrm{C} 1, \mathrm{C} 2, \mathrm{C} 3$ and $\mathrm{C} 4$ are the different loading conditions of the ship. 
The maximum permissible deadweight moment isn't equal zero in case of the light displacement of the ship because of the ship has the adequate reserve of stability in the light condition And accordingly it will have a permissible deadweight moment in this condition [14].

\subsection{Analysing Model}

A passenger yacht (Figure 3) has been used as the analysing model, this yacht has the following particulars as shown in Table 1 with the knowledge that the full load departure means all tanks are full except the sewage tanks have only $10 \%$ capacity, number of crew and all passengers are full.

Table 1: The particulars of the analysing model

\begin{tabular}{|l|l|}
\hline \multicolumn{2}{|c|}{ The Principal Characteristic } \\
\hline $\mathrm{L}$ & $42 \mathrm{~m}$ \\
\hline $\mathrm{B}$ & $9.4 \mathrm{~m}$ \\
\hline $\mathrm{D}$ & $4.4 \mathrm{~m}$ \\
\hline $\mathrm{T}$ & $2.2 \mathrm{~m}$ \\
\hline $\mathrm{CB}$ & 0.638 \\
\hline$\Delta$ & $460 \mathrm{ton}$ \\
\hline KG & $2.87 \mathrm{~m}$ \\
\hline crew & 10 persons \\
\hline passengers & 50 person \\
\hline V & $12 \mathrm{kn}$ \\
\hline
\end{tabular}

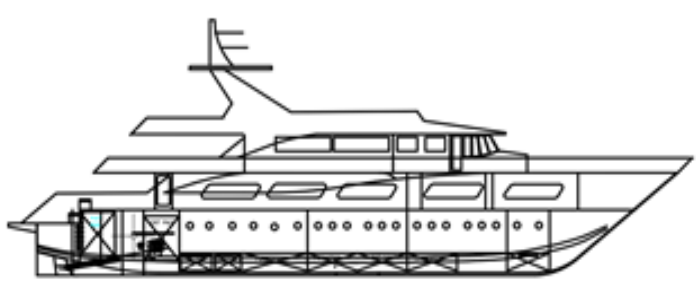

Figure 3 : Profile of analysing model

The analyses of stability requirements are performed using Maxsurf Stability Enterprise Software. This program is applied to the analysing models using either of the following approaches:

A. For the same model's length, depth and displacement, breadth decreases with an increment of both 5 and 10 percent successively and increases with the same percentage.

B. For the same model's breadth, length and displacement of the model, depth decreases with an increment of both 5 and 10 percent successively and increases with the same percentage.

C. For the same model's breadth, depth and displacement of the model, length decreases with an increment of both 5 and 10 percent successively and increases with the same percentage.

E. For the same model, but with changing the length of the damaged compartment.

Note that:

Damage stability analysis adopts the same load case but with assuming the occurrence of damage at tanks and compartments which are shown in the Figure 4 by red color.

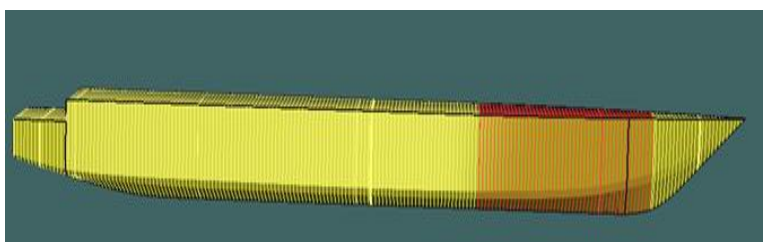

Figure 4 : assumption of damage area up to main deck (symmetrical flooding).
To calculate the moment of crowding of all passengers to one side, it is assumed that all 50 passengers are shifted from the center line to distance equal $0.5 \mathrm{~B}$.

All the results after the changes in the original vessel are function of the percentage of the increase or decrease in relation to the origin of the original ship.

\subsubsection{Sensitivity analyses of stability properties to ship's beam}

To study the sensitivity analyses of tested intact stability properties to ship beam, the both

Figure 5 and Figure 6 discuss the here-coming conditions. Here, where the limiting criterion (B) is applied to the model, i.e., changing the breadth systematically for the same length and height.

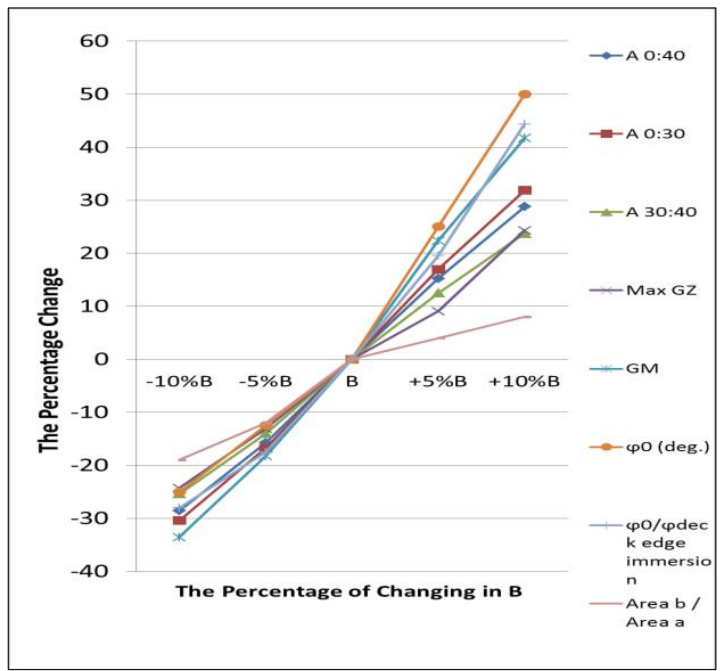

Figure 5 : intact stability properties which are directly change with changing $B$.

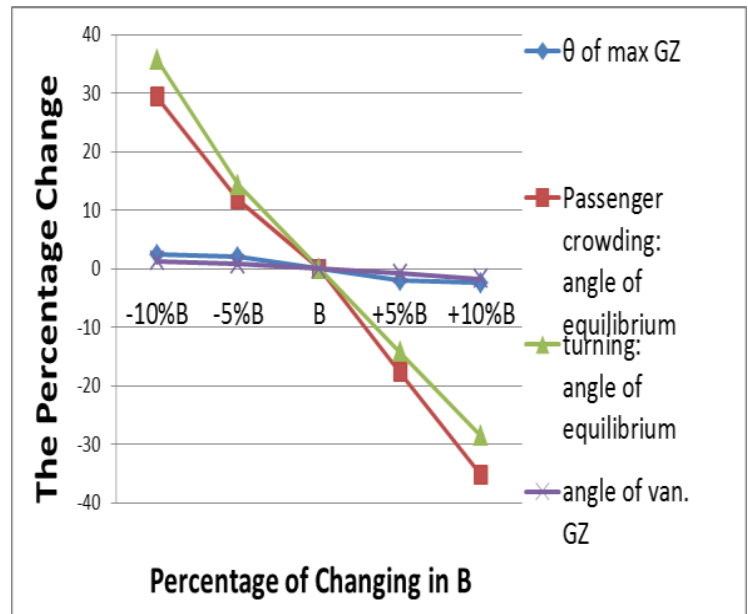

Figure 6 : intact stability properties inversely change with changing $B$.

To study the sensitivity analyses of tested damage stability properties to ship beam, the Figure 7 discusses the herecoming condition. Where, the limiting criterion (B) is applied to the model, i.e., changing the breadth systematically for the same length and height. 


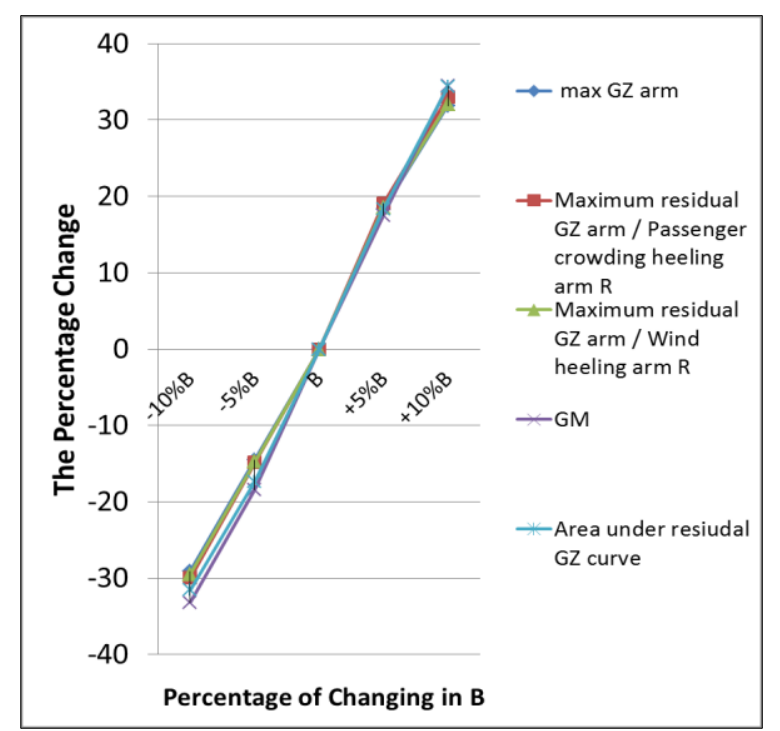

Figure 7 : Damaged stability properties with changing $B$

To study the sensitivity analyses of limiting KG to ship's beam, the Figure 8 is related to intact limiting $K G$ analysis while Figure9 is related to damaged limiting KG analysis verse displacement from 350 ton to 460 ton.

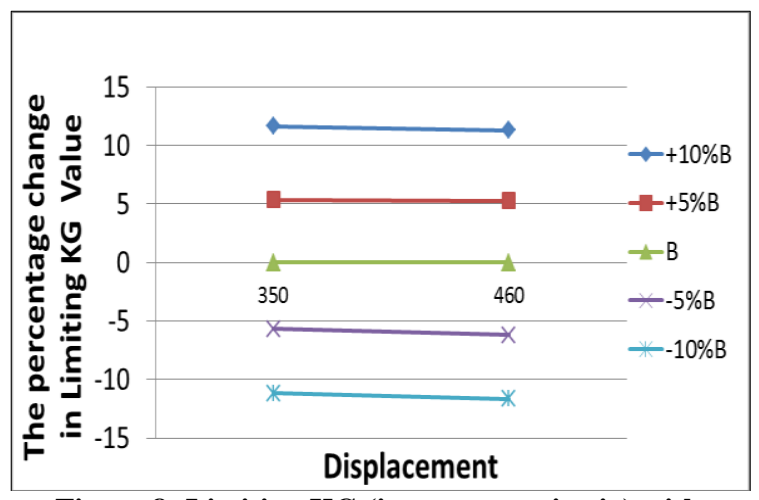

Figure 8: Limiting KG (intact case criteria) with changing $B$

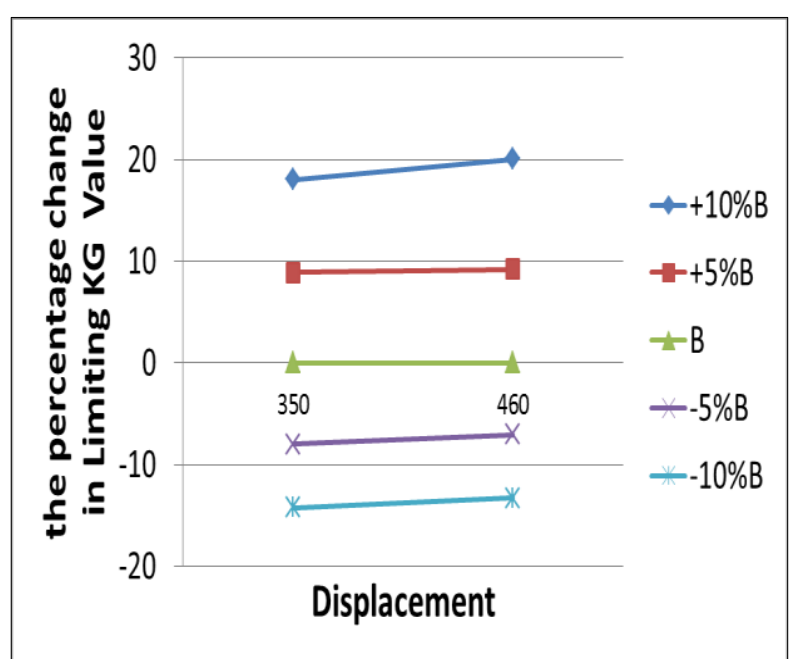

Figure9: Limiting KG (damaged case criteria) with changing $B$

\subsubsection{Sensitivity analyses of stability properties to ship's depth}

To study the sensitivity analyses of tested intact stability properties to ship depth, both Figure 10 and Figure 11 discuss the here-coming conditions. Here, the limiting criterion (D) is applied to the model, i.e., changing the depth systematically for the same length and breadth; assuming the same KG.

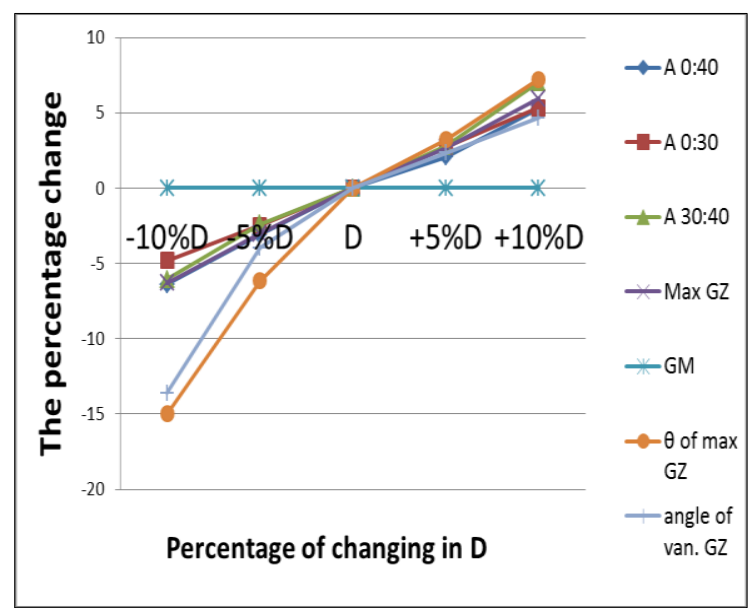

Figure 10 : intact stability properties which are directly change with changing $D$.

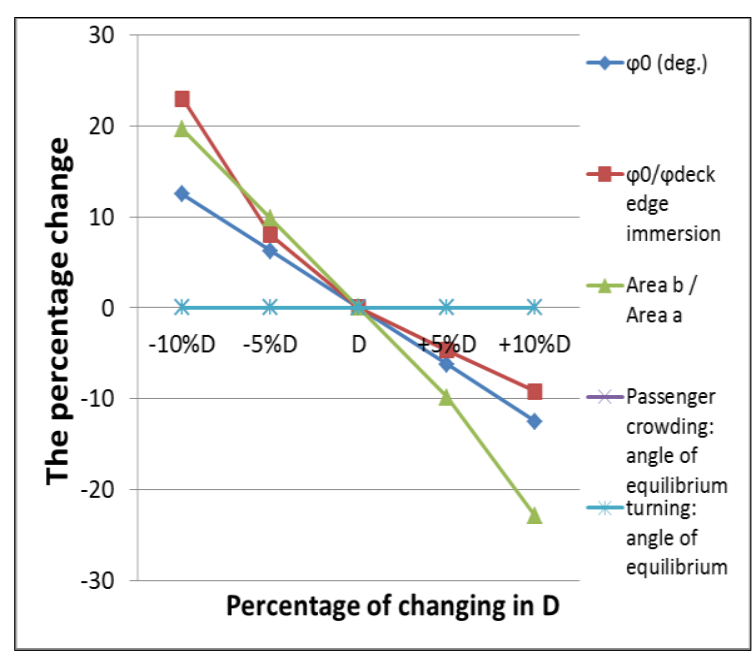

Figure 11 : intact stability properties inversely change with changing $D$.

To study the sensitivity analyses of tested damaged stability properties to ship depth, the Figure 12 discusses the here-coming condition. Where, the limiting criterion (D) is applied to the model, i.e., changing the depth systematically for the same length and breadth.

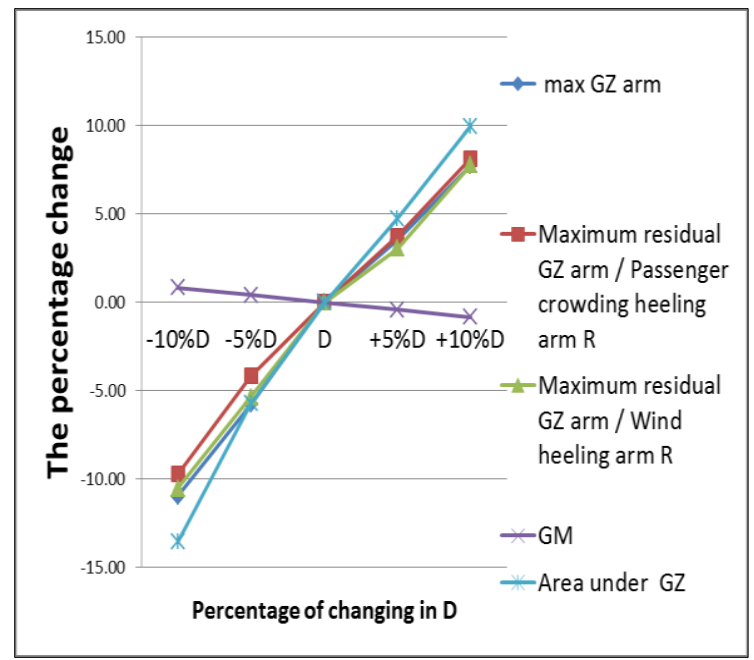

Figure 12: Damaged stability properties with changing D 
To study the sensitivity analyses of limiting KG to ship's depth, the Figure 13 is related to intact limiting KG analysis while Figure 14 is related to damaged limiting KG analysis verse displacement from 350 ton to 460 ton.

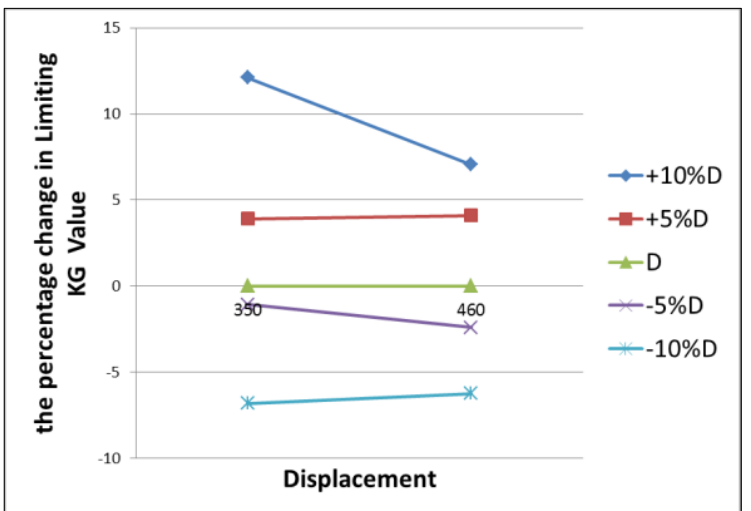

Figure 13 : Limiting KG (intact case criteria) with changing $D$

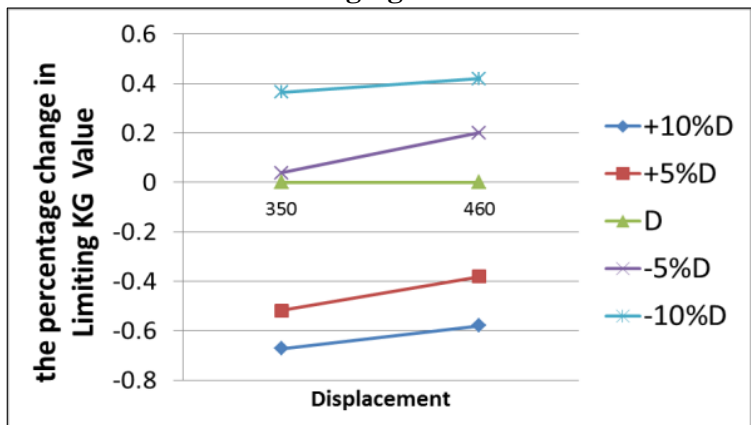

Figure 14: Limiting KG (damage case criteria) with changing D

\subsubsection{Sensitivity analyses of stability properties to ship's length}

To study the sensitivity analyses of tested intact stability properties to ship length, both Figure 15 and Figure 16 discuss the here-coming conditions. Here, the limiting criterion (L) is applied to the model, i.e., changing the length systematically for the same depth and breadth; assuming the same KG.

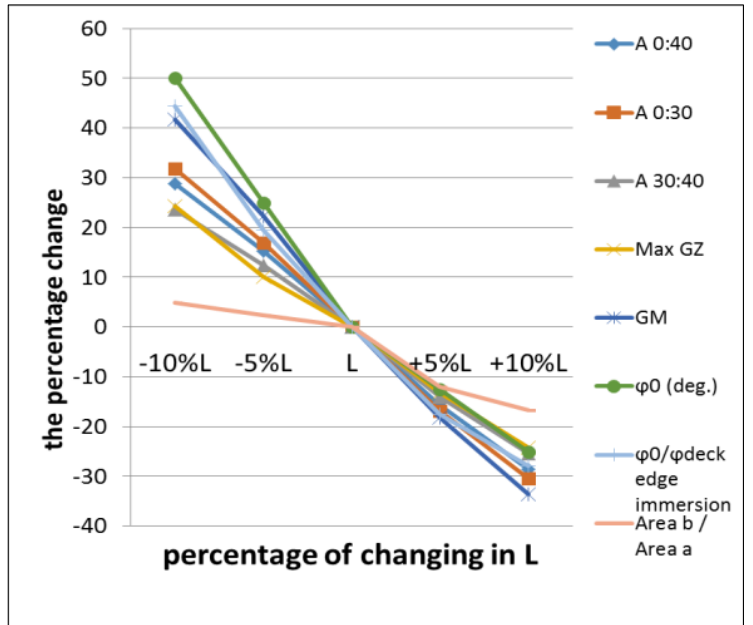

Figure 15 : intact stability properties which are directly change with changing $L$

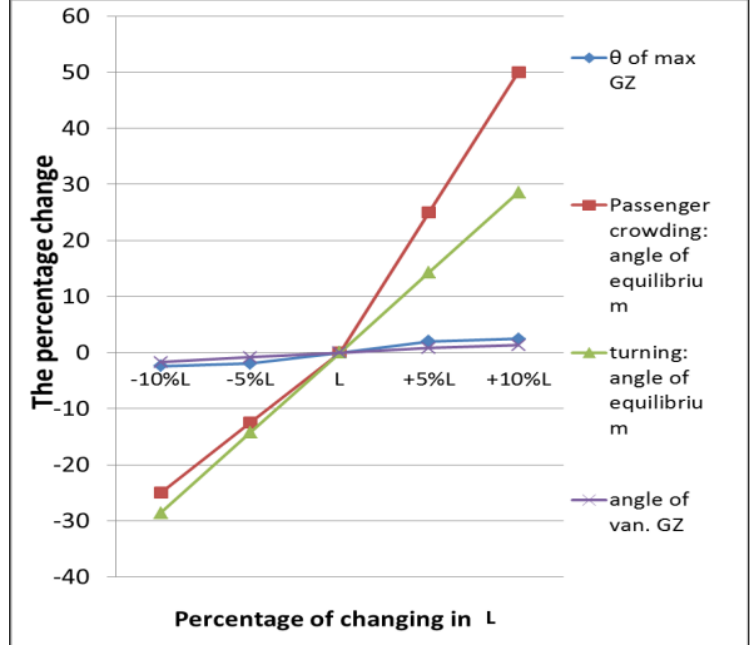

Figure 16 : intact stability properties inversely change with changing $L$

To study the sensitivity analyses of tested damaged stability properties to ship length, the Figure 17 discusses the here-coming condition. Where, the limiting criterion (L) is applied to the model, i.e., changing the length systematically for the same depth and breadth; assuming the same KG.

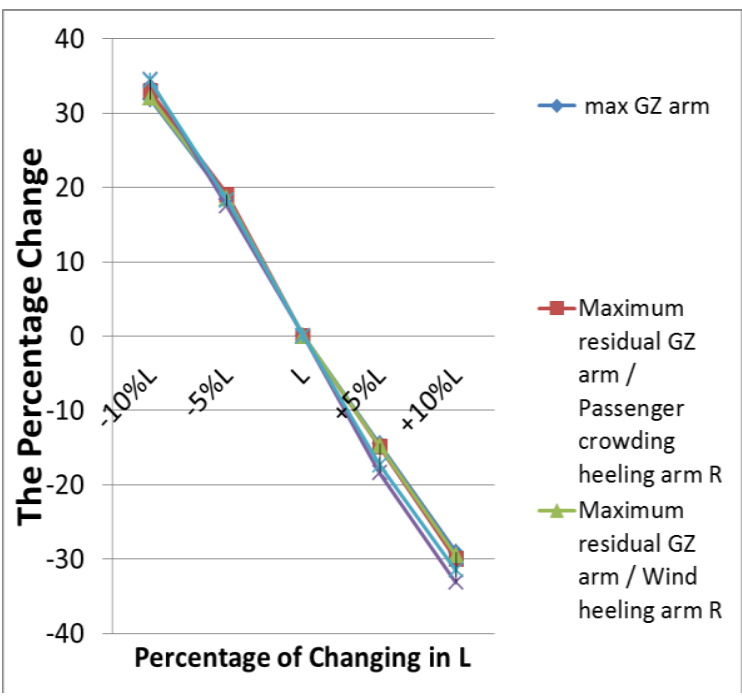

Figure 17 : Damaged stability properties with changing $\mathbf{L}$

To study the sensitivity analyses of limiting KG to ship's length, the Figure 18 is related to intact limiting KG analysis while Figure 19 is related to damaged limiting KG analysis verse displacement from 350 ton to 460 ton. 


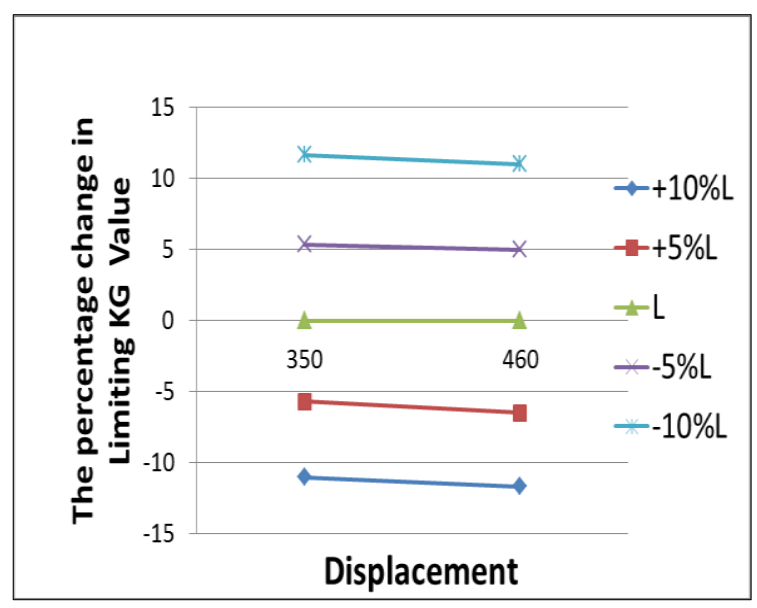

Figure 18 : Limiting KG (intact case criteria) with changing $L$

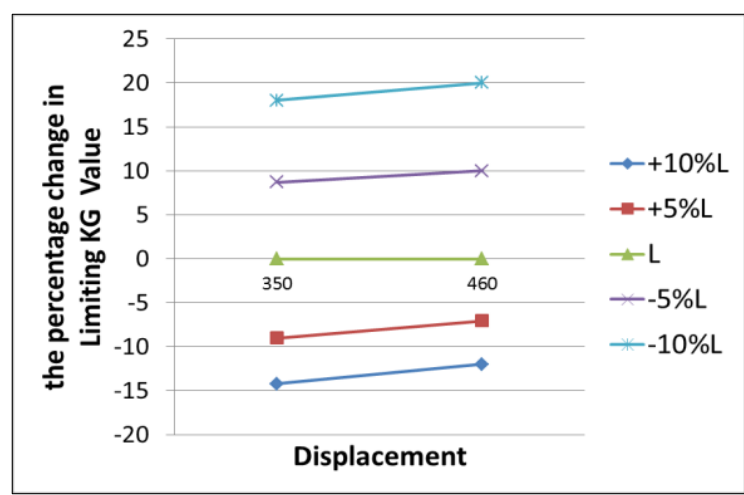

Figure 19 : Limiting KG (damaged case criteria) with changing $L$

\subsubsection{Sensitivity analyses of stability properties to changing the length of a damaged compartment}

To study the sensitivity analyses of tested damaged stability properties to the length of a damaged compartment, the Figure 20 discusses the here-coming condition.

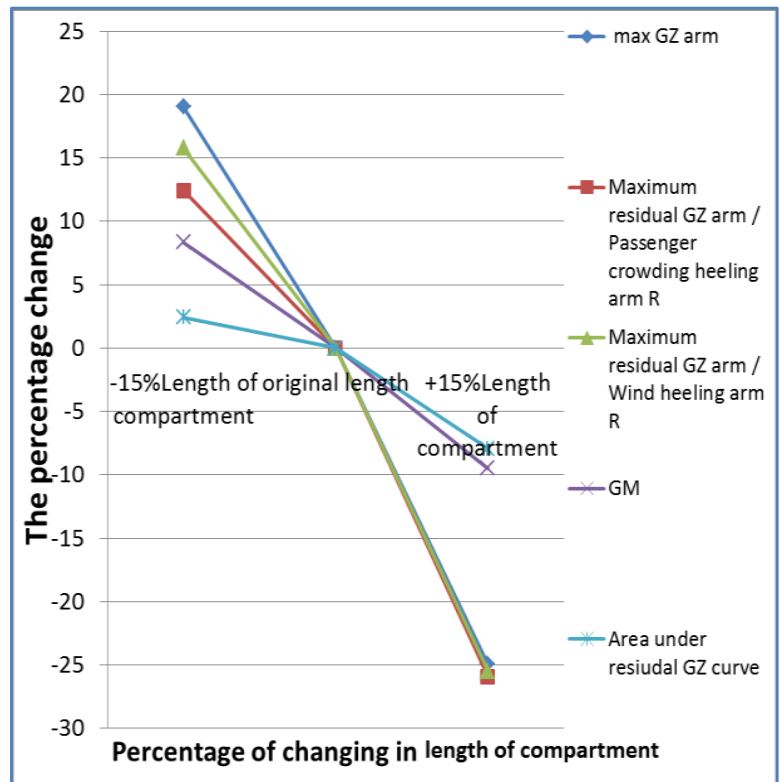

Figure 20 : Damaged stability properties which are change with changing the length of a compartment
To study the sensitivity analyses of damaged limiting KG to the length of a damaged compartment, the Figure 21 discusses the here-coming conditions where damaged limiting KG curve is verse displacement from 350 ton to 460 ton.

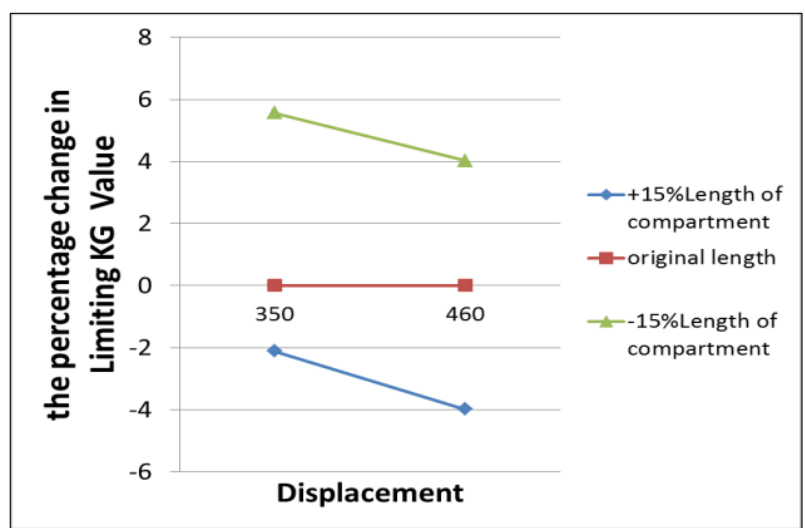

Figure 21 : Limiting KG (damaged case) with the length of a compartment

\subsection{DISCUSSION OF RESULTS}

\subsubsection{Intact stability criteria analysis}

As a culmination of the present study, the following observations have been deduced.

In

Figure 5 and Figure 6, it is found that for lower L/B:

- The areas under GZ curves until $40^{\circ}$ are increasing.

- The value of max GZ has increased.

- The value of initial GM has increased.

Whereas, for the same figures:

- The angle of max GZ has decreased signifying it started earlier.

- The range of positive stability has decreased.

- The angles of equilibrium due to passenger crowding and due to turning have decreased.

- The deck immersion angle has decreased.

Whether, In Figure 10 and Figure 11, it is found that for lower L/D:

- $\quad$ Areas under GZ curves until $40^{\circ}$ are increased.

- Value of max GZ has increased.

- Value of initial GM has considered unchanged

- $\quad$ Angle of max GZ has increased.

- $\quad$ Range of positive stability has increased.

- Angle of equilibrium due to passenger crowding and due is considered unchanged

- Deck immersion angle has increased.

- Weather criteria have decreased.

As for, in Figure 15 and Figure 16, although there is no direct relationship between the length of the vessel and its intact stability, yet the changes resulting from these analyzes are factors of the ratio of length to breadth. The shorter the vessel with a shorter length and wider breadth improves significantly the stability of the ship.

\subsubsection{Damaged stability criteria analysis}

It was found that in the final condition after assuming a damage to a specific compartment:

In Figure 7, it is found that at the lower L/B: 
- $\quad$ The higher value of max GZ after damage.

- The higher value of GM

- $\quad$ Area under the residual GZ curve has increased

In Figure 12, it is found that at the lower L/D:

- $\quad$ The higher value of max GZ after damage.

- Slight change of GM.

- The Area under the residual GZ curve has increased.

Whereas, for Figure 18 the changes resulting from these analyzes are factors of the ratio of length to depth. This leads to larger freeboard which improves the ship's stability, as it produces reserve buoyancy in damaged condition.

Referring to Figure 20, it is evident that the shorter the compartments under bulkhead deck are the best for damage calculations.

\subsubsection{Limiting $\mathrm{KG}$ analysis}

In Figure 8, Figure9, Figure 13, Figure 14, Figure 18 and Figure 19; it is clear that the max allowable value for $\mathrm{KG}$ is increased for ships which has lower $\mathrm{L} / \mathrm{B}$ or $\mathrm{L} / \mathrm{D}$ for intact and damaged conditions. The reason is that increased breadth improves significantly the stability of the ship and the increased depth increases the reserve displacement.

Referring to damage calculations in Figure 21, it is evident that the shorter the compartments under bulkhead deck the higher the limiting KG.

\section{CONCLUSION}

For design purposes, the investigation of the effects of ship's design parameters on the limiting $\mathrm{KG}$ in intact and damaged conditions may help in better choice of ship's proportions which insure a sufficiently high limiting KG for the ship satisfying the IMO-SOLAS criteria.

Stability criteria are certainly dependent on the dimensions and shape of the vessel, and accordingly, determining the Limiting Deadweight moment and the limiting KG standards that meet specific criteria for damage and stability in the initial stages of vessel design $\mathrm{KG}$ are very important to measure the vessel's ability to withstand severe damage during service, requiring that the designer is aware of the relationship between this measure and the ship's dimensions.

The lower L/B and/or lower L/D produce higher limiting KG and higher margin of Stability properties; i.e., the high, short and wide hulls are better. Nonetheless, Stability criteria are not the single criteria, although it is the most important in determining the dimensions of the ship. Nevertheless, all factors have to be taken into account. For instance, the increase in the height of the passenger ship leads to improve the stability as a result of the increased reserve buoyancy in damaged condition. Furthermore, the increase in the height leads to an increase in the ship's dead weight consequently its cost. Moreover, the ratio $\mathrm{B} / \mathrm{H}$ and its relation to the ship's transverse strength should not be ignored.

The wider hulls with higher depth are better for limiting $\mathrm{KG}$, but when determining $\mathrm{L} / \mathrm{B}$ we must take into account the deck immersion angle. The lower $\mathrm{L} / \mathrm{B}$ reduces the deck immersion angle.

With reference to damage calculations, it is clear that the shorter the compartments under bulkhead deck the higher the limiting $\mathrm{KG}$, but the shortening of, any compartment must be handled carefully, especially, if the compartment in question is the engine room, as it is important to facilitate the fitting of equipment and movement of personnel through the compartment . The shortening may also increase the number of watertight bulkheads and consequently the light weight of the ship.

\section{REFERENCES:}

[1] M. ; Lord, "The Loss of the Titanic; 1912.," Station. Off. ISBN 978-0-11-702403-8., 1999.

[2] R. W. Joughin, "The Revised SOLAS Regulations for Ro-Ro Ferries," Warsah Marit. Cent., 2008.

[3] H. Chua-Eoan, "Disasters: Going, Going," Time Mag., 1991.

[4] A. Francescutto and A. D. Papanikolaou, "Buoyancy, stability, and subdivision: From Archimedes to SOLAS 2009 and the way ahead," Proc. Inst. Mech. Eng. Part M J. Eng. Marit. Environ., vol. 225, no. 1, pp. 17-32, 2011.

[5] C. C. Andrei, "Actual Ships Stability Problems and the Influence on Safety of Navigation," Ed. Digit., 2016.

[6] A. Francescutto, "Intact stability criteria of ships Past, present and future," Ocean Eng., vol. 120, no. 2001, pp. 312-317, 2016.

[7] IMO, "International Code of Intact Stability," IMO Publ., 2008.

[8] Rahola, "The Judging of the Stability of Ships and the Determination of the Minimum Amount of Stability Especially Considering the Vessels Navigating Finnish Waters (Ph.D.thesis).," TechnicalUniversityof Finland,Helsinki., 1939.

[9] A. P. Ã and E. Eliopoulou, "the development of the new harmonised damage stability regulations for dry cargo and passenger ships," no. September, 2008.

[10] A. Papanikolaou, "Review of regulatory framework of Damage Stability of Dry Cargo and Passenger Ships," NTUA-SDL,US, no. Nov, 2015.

[11] D. G. Younis, "The Limting KG for Intact Stability Requirements Of Passenger Ships," portsaid Sci. Eng. Bull. Vol.7, 1995.

[12] J. W. Sebastian, Parametric prediction of the transverse dynamic stability of ships. Monterey, California. Naval Postgraduate School, 1997.

[13] SOLAS, "International Convention for the Safety of Life at Sea," IMO Publ., no. June 1960, p. 2008, 2009.

[14] A. R. Lester, Merchant Ship Stability. Elsevier, 2013.

$$
\begin{aligned}
& \text { دراسة حساسية خصائص الاتزان فى الحالة السليمة }
\end{aligned}
$$

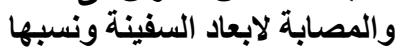

$$
\begin{aligned}
& \text { ملخص البحث } \\
& \text { تناول البحث العزم الحرج للوزن الميت أو مركز التقل الحرج } \\
& \text { للسفن و الذى يضمن كفاية إنز ان السفينه في الحالتين وطرق حسابه رياضيا. } \\
& \text { كما تناول عمل تعديلات لسفينة ركاب صغيده نحت الانشاء على }
\end{aligned}
$$

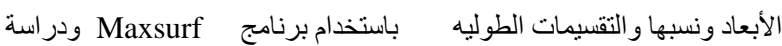

$$
\begin{aligned}
& \text { نأثير ها فى نسبه التغير التى حدثت في حسابات معايير السلامه فى الحالة السليمة }
\end{aligned}
$$

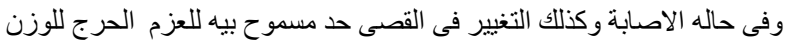

$$
\begin{aligned}
& \text { الميت فى الحالتين. } \\
& \text { واخبرا احتوى على سرد للنتائج التى تم الحصول عليها من }
\end{aligned}
$$

